Boletín de la Sociedad Botánica de México 53: 135-139, 1993

DOI: 10.17129/botsci.1421

Bol. Soc. Bot. México 53:135-139 (1993)

\title{
Obito. Howard Scott Gentry (1908-1993)
}

El pasado $1^{\circ}$ de abril de 1993, dejó de existir en Tucson Arizona el Dr. Howard Scott Gentry, destacado botánico, gran conocedor de México y uno de los botánicos de campo más reconocidos de Norte América.

Hijo de Irvin y Elizabeth Gentry, nació en Temecula, California al norte de San Diego, el 10 de Diciembre de 1908. A lo largo de su fructífera vida realizó importantes aportaciones al conocimiento de la botánica mexicana, describiendo nuevos taxa, haciendo estudios regionales o realizando investigaciones de tipo monográfico como aquellos que hizo sobre la familia Agavaceae, de la cual era considerado una de las autoridades mundiales.

Sin pretender hacer una reseña exhaustiva acerca de sus trabajos en México, si quisiera destacar parte de su labor como botánico en nuesto país. Para esta finalidad, dos trabajos me han sido particularmente útiles la obra monumental de Ida K. Langman (1964) sobre la literatura botánica de México y el trabajo de Lindsay (1955) sobre colectores botánicos de California.

El Dr. Gentry desde 1933, comenzó a interesarse por la flora y la vegetación del noroeste de México, en el otoño de ese año, viajó desde Cajeme (hoy, Ciudad Obregón, Sonora) hacia el oriente, a través del río Cedros y el Arroyo Guarajay, afluentes del Rio Mayo. Las plantas que herboriza, unas las manda a la Universidad de Michigan y otras a la de Stanford. En el otoño de 1934 comienza a recolectar en San Bernardo, al nordeste de Alamos y prácticamente en esa fecha, comienza el trabajo sobre la vegetación y los aspectos florísticos del Valle del Río Mayo, estudio que le ocupa de manera intermitente 27 meses de trabajo de campo hasta noviembre de 1939, en una zona, en ese tiempo, prácticamente desconocida desde el punto de vista botánico; ya para esas fechas, acompañado por su esposa, Marie Ann Cech Gentry, su eficaz colaboradora y compañera de toda su vida; trabajo en el cual recolectaron 3,200 números que representan 1276 especies, de las cuales más de 90, resultaron nuevas para la ciencia. Estos trabajos culminaron en noviembre de 1942, con la publicación de: Plantas del Río Mayo, un estudio de la flora y la vegetación del Valle del Río Mayo, Sonora.

Alternando sus épocas de recolecta en Sonora, viaja hacia Baja California, en abril de 1938 a Santa Rosalía, Loreto, Puerto Escondido y a las cañadas de la Sierra de La Giganta. 
De noviembre de 1938 a abril de 1939, viaja, herborizando desde Tijuana a la región de Los Cabos, en las Sierra de la Giganta y de La Laguna parte del trabajo lo realiza viajando de una forma que llegó a ser cotidiana en él, sobre el lomo de mulas o caballos. En 1940 describe una nueva especie del género endémico de Baja California, Vizcainoa. En 1942, viaja a Tamaulipas recolectando algunos números.

A partir de septiembre a noviembre de 1943, viaja por el estado de Durango buscando áreas favorables para experimentar con el cultivo de "Guayule" (Parthenium argentatum), para esas fechas trabajaba para el Departamento de Agricultura de Estados Unidos (USDA) en la oficina de investigación de plantas laticíferas. Un segundo viaje a la zona de Durango lo realiza acompañado de su padre, Irvin M. Gentry, tiempo en el cual realiza los muestreos de la vegetación y completa parte de su trabajo de la tesis doctoral sobre los pastizales de Durango, la cual presenta en 1946 en la Universidad de Michigan sobre "The Durango Glasslands". En 1957 el Ing. Efraím Hernández-Xolocotzi, uno de los agrostólogos mas notables de México, traduce la obra al español editandola el Instituto Mexicano de Recursos Naturales Renovables de México; este trabajo es uno de los más completos y detallados sobre una parte de los pastizales de México.

En 1946 publicó un trabajo sobre la vegetación de la Sierra Tacuichamona en Sinaloa y otro sobre la Sierra Surotato, también en Sinaloa. En ese año publica un nuevo género de (Cucurbitaceae, Anomalosicyos. Vuelve a Baja California en marzo de 1947, en donde en Catavinia y Marmolito, recolectó unos 280 números. En noviembre de este año realizó otro viaje a la Sierra del Vizcaino herborizando 224 números; publicó además dos especies nuevas del género Mimulus (Scrophulariaceae) de Sinaloa.

En 1948, vuelve a Baja California llegando a Ensenada y alrededores, donde realiza algunas colectas. Publica en este año, un trabajo sobre adiciones a la flora de Sinaloa y Nuevo León, describiendo 19 nuevos taxa.

A principios de 1949, revisita la Sierra del Vizcaino, colectando en la Sierra de Las Pintas y la montaña Cocopa. En 1949, se publica el trabajo sobre las plantas terrestres colectadas durante la expedición del Velero III, de la Fundación Allan Hancock entre 1937 y 1941, la cual abarcó las Islas Cedros, San Benito, Revillagigedo y Tres Marías.

Publica en 1950, un trabajo sobre la taxonomía y evolución del género Vaseyanthus (Cucurbitaceae) y otro sobre el género Dalea (Leguminosae) con claves y descripciones para nuevas especies de la Sierra Madre Occidental y parte del Nuevo México y Arizona.

A partir de 1950 hasta 1971, se incorpora como recolector de germoplasma de cultivares al Departamento de Agricultura (USDA), lo cual le permite viajar a través de Estados Unidos a Panamá, parte de la India, Europa Occidental y Africa. Desde 1951, parte de sus colectas las realiza acompañado de Juan Argüelles de San Bernardo, Sonora. Prosigue con sus viajes de colecta botánica en México, publicando en 1956 un nuevo Gossypium (Malvaceae) de Michoacán y en 1957 una nueva Yucca de Sonora, Yucca grandiflora. En octubre de 1957 comienza la investigación taxonómica de los Agaves y grupos relacionados, originalmente en un programa de búsqueda de fuentes 
vegetales de cortisona, recolectando plantas productoras de sapogenina, como las de los géneros Yucca y Agave.

Viaja a México y en octubre de 1960 asiste al 1er. Congreso Mexicano de Botánica, presentando un trabajo sobre Agave colimana y Agave geminiflora.

En 1963, publica un interesantísimo estudio etnográfico, sobre los indios Warihio de Sonora y Chihuahua, cabe decir que además del español que hablaba con cierta fluidez salpicado de arcaismos producto de su trato con los rancheros y gente de la sierra, dominaba el dialecto Warihio y parte del Mayo, lo que le permitió incorporar en sus notas de campo y luego en sus libros además de los nombres locales de las plantas, información acerca de los usos y propiedades conocidas por los indígenas.

A partir de 1971 se incorpora al Jardín Botánico del Desierto en Phoenix, Arizona.

En marzo de 1972, el Departamento de Agricultura (USDA) publica su obra sobre la familia Agavaceae en Sonora; de donde estudia especies de Yucca, Nolina, Dasylirion, Manfreda y Agave. De estos géneros 13 son especies nuevas de Agave, 2 de Yucca y 1 de Hesperaloe; además de algunas subespecies en Agave.

En diciembre de 1972, asiste al V Congreso Mexicano y I Latinoamericano de Botánica en México, D.F. Posteriormente, la Sociedad Botánica de México, lo distinguió como Socio Honorario de la misma.

Sus visitas y viajes a Baja California rinden el esperado fruto pues en diciembre de 1978, la Academia de Ciencias de California, publica su trabajo de Agaves de Baja California en donde describe 23 taxa, de los cuales 4 son nuevas especies y 8 nuevas subespecies. Nuevamente, como ya era usual en sus trabajos incorpora datos económicos e históricos recabados de los pobladores indígenas y o de los rancheros.

Finalmente, en 1982 la Universidad de Arizona publicó el trabajo más completo y detallado sobre los Agaves de Norte América Continental, en el cual hace el tratamiento taxonómico de las 136 especies que reconoce; para cada una proporciona: una breve descripción taxonómica; notas sobre su posición taxonómica, sus rasgos distintivos; distribución y habitat; usos, pasados y presentes; nombres vernáculos y aún datos sobre su cultivo y propagación.

En 1965 y 1967, tuve oportunidad de acompañarle en unos de sus múltiples viajes realizados a México, buscando germoplasma de cultivares, principalmente frijol y maiz, además de los Agaves, Yucas y grupos afines. Era para quien le acompañara, un libro abierto, siempre dispuesto a compartir sus vastos conocimientos, desde las 6:00 horas, en que generalmente se comenzaba la diaria labor, después del, para mi, ligero (ligerísimo) desayuno consistente en un café negro con un poco de pan tostado con mantequilla o mermelada y ya... hasta las 12:30 ó 13:00 en que realizabamos el almuerzo y luego hasta las 18:00 o 19:00 en que opíparamente cenábamos, para luego numerar y preparar el material, auxiliado con las notas que en forma detallada y prolija había recabado de cada planta en forma directa del campo, de los campesinos o de los vendedores de los mercados; en no pocos casos, algunos se negaron a proporcionar datos 
de sus semillas, pues al ver a un "gringo", preguntando si vendían frijoles, de donde venían, si eran de reciente cosecha y demás datos, el comerciante se entusiasmaba ante la posibilidad de una venta sustancial y a lo mejor hasta con una ganancia adicional, el desengaño, a veces desencanto, venía cuando le decíamos que solo necesitábamos medio kilo de cada tipo de frijol... creo que más de una vez, allá por la Tierra Caliente, en Guerrero y Michoacán alguna "mentada" nos llevamos o cuando menos la negativa a proporcionar datos.

Su charla, de lo más amena, estaba salpicada de arcaismos, seguramente producto del trato con rancheros, arrieros e indígenas del noroeste de México con quienes departió muchas veces y con quienes practicaba su español; sus enseñanzas no se limitaban a los aspectos botánicos o ecológicos, sino que a veces fueron de responsabilidad y respeto para con los demás. Alguna vez viajando en una camioneta, "Dodge Power", con el emblema del Departamento de Agricultura de Estados Unidos, la cual siempre manejó en ese viaje, en repetidas ocasiones, yo, ansioso de manejar esa camioneta por las brechas, lo cual siempre me ha gustado, le insistía que si quería que le ayudaba, que si se sentía cansado yo manejaba, que yo manejaba una camioneta parecida (mentira) del Jardín Botánico; ante mi insistencia después de 3 ó 4 días, me dijo con esa forma tan peculiar de hablar el español: "mire Francisco, el tío Sam, me da la "troca" para trabajar, para juntar frijoles, si yo se la presto y algo sucede, el tío Sam, va a decir, ¿Howard, por qué prestaste un vehículo oficial que estaba a tu cargo? ¿entiende Francisco?"; claro que entendí, y el siguió manejando, por cierto con mucha habilidad, por esas brechas en la Tierra Caliente.

En otra ocasión, le acompañé a buscar flores de una Yucca en la Sierra de la Ventana en el límite de Sonora y Chihuahua; llegamos a Navojoa, de ahí a Alamos y luego a San Bernardo, lugares que él conocía como la palma de su mano. En San Bernardo el doctor buscó al señor Juan Argüelles, para él, Juanito", quien lo había acompañado en nuemerosas ocasiones, desde mucho tiempo atrás. Los tres salimos cada quien montado en una mula, seguimos por Tetasuare hacia la Sierra de La Ventana, pasamos por un rancho en donde comimos un buen pedazo de carne de venado, al anochecer ya en la parte alta de la Sierra, Juanito desensilló las bestias y procedimos a hacer una fogata y un café para la cena; el doctor unos días antes, en Toluca había comprado una magnífica cobija de lana, y Juanito llevaba un buen "gabán", siendo yo, el menos abrigado; sin saber que en algún momento acamparíamos no iba preparado, al principio y durante la cena, alrededor de la fogata, no sentí el frío, pero más tarde, la temperatura descendió tanto que terminé tapándome con los "aparejos" de las mulas, lo cual hizo que el doctor se sientiese algo apenado conmigo. Al día siguiente arribamos por la tarde a un rancho de un amigo de Juanito, nos recibió muy amablemente, primero nos "ensilló", (nos proporcionó una silla), luego nos ofreció un "refino", un trago de "bacanora", después me enteré que este es uno de los mejores aguardientes ("mezcales"), elaborado a partir de Agave pacifica; previamente el doctor había comprado algunos alimentos enlatados 
(jamón, chorizo, quesos, galletas, etcétera), los cuales proporcionó a la señora de la casa con la indicación por parte de él, que eran para que nos preparara algo de comer. A la hora de la cena y después de una amena charla de nuestro anfitrión, nos acomodamos alrededor de una mesa; la cena consistió en un caldo de verduras, con "gordas" (tortillas) de maíz y un excelente café de grano. La señora de la casa cuando el caldo con verduras estaba a punto de hervir, desprendió un pedazo de hueso con grasa de cordero o de chivo, que tenía colgado en el techo encima del fogón, lo metió a la olla lo agitó en el caldo durante unos segundos, lo sacudió y volvió a colgarlo; el resto de la comida fué un plato de frijoles, y salsa picante; a la mañana siguiente el almuerzo fué el mismo; por la tarde, el dueño del rancho nos recibó con otro "refino", su amena charla y luego otra vez la misma cena y el exquisito café. Hasta el día siguiente, ya de regreso, después de otro almuerzo igual, pero sin "refino" pues ese sólo era por la tarde, el doctor se atrevió a comentar que la señora se había quedado con nuestros comestibles y que ni por enterada se había dado que los comestibles eran para que comieramos todos. Unas horas después nos desquitamos en Alamos con una buena carne asada, un buen baño con agua caliente y una mullida y para mi, calientita cama.

En otra ocasión que viajó a México a recolectar plantas llegó al Jardín Botánico de la UNAM, después de platicar con él y mencionar su itinerario, le manifesté mi interés por acompañarlo, pues quería seguir aprendiendo de él, después de guardar silencio unos instantes, me dijo que, como él, iba a aceptar que un biólogo recibido ya, profesor en la Facultad de Ciencias, etcétera fuese como su ayudante en el campo, que eso no podía ser. Detalles de este tipo eran lo que hacían diferente, muy diferente, al doctor Gentry y que se ganara el afecto y el respeto de los demás.

Hoy se ha ido, pero como los grandes hombres su obra persiste y su recuerdo nos acompaña. Descanse en paz.

\section{LITERATURA CITADA}

LANGMAN, I.K. 1964. A selected guide to the literature on the flowering plants of Mexico. University of Pennsylvania Press, Philadelphia 1015p.

LINDSAY, G.E. 1955. Notes concerning the botanical explorers and exploration of Lower California, Mexico. Belvedere Scientific Fund, San Francisco. 105p. 1 mapa.

FRANCISCO GonZÁLEZ MEDRANO, Departamento de Botánica, Instituto de Biología, Universidad Nacional Autónoma de México, Apdo. Postal 70-233, Deleg. Coyoacán, 04510, México, D.F. 